\title{
Resenha
}

\section{Avanços e retrocessos do direito à saúde no Brasil: uma análise crítica ${ }^{1}$}

\author{
Sandra Mara Campos Alves²
}

O direito à saúde, reconhecido na Constituição de 1988 como direito social e de cidadania, representou importante conquista da sociedade brasileira, fruto de intensa mobilização social articulada em tempos de restrição democrática. Todavia, a implantação do sistema de saúde idealizado pelos sanitaristas, ainda se encontra em fase de implementação, e ao longo desse processo, observa-se avanços e retrocessos.

Nesse sentido, a obra é pertinente e atual vez que apresenta uma análise dos retrocessos doutrinários e institucionais que atingiram o direito à saúde ao longo dos últimos 28 anos, ao tempo que também apresenta alternativas para que seja possível uma reversão desse quadro.

Logo na introdução o autor apresenta uma questão que, segundo ele, representa a essência do debate da sua obra, que aqui reproduzo: "Como se dá a origem e desenvolvimento do direito fundamental social à saúde desde sua constitucionalização até a conjuntura atual, tendo em vista as mudanças jurídicas, políticas e econômicas, avanços e retrocessos por que passou o direito sanitário no Brasil no decorrer desse período; e quais as alternativas para sua completa efetivação?" (p. 21).

A partir dessa indagação, a obra se divide em três capítulos, onde o autor insere os diversos pontos de sua abordagem - da reforma sanitária às alternativas de enfrentamento ao retrocesso social na saúde - para então apresentar suas considerações finais.

O Capítulo 1 apresenta uma análise histórico-dialética do contexto político, social e econômico brasileiro nos diversos momentos da reforma sanitária, desde a reivindicação por um novo modelo sanitário, a implantação das políticas de saúde na década de 1990, e análise a partir dos anos 2000, com os governos Lula e Dilma.

Nesse contexto, o autor apresenta os fatos tradicionais e imutáveis desse processo de reivindicação do direito à saúde e as ações realizadas pelo movimento da reforma

1 Cunha JRA. Avanços e retrocessos do Direito à Saúde no Brasil: uma análise crítica. Rio de Janeiro: Multifoco, 2016. ISBN 978-85-5996-072-3

${ }_{2}^{2}$ Advogada, Doutoranda em Saúde Coletiva pela Universidade de Brasília-UnB. Email: smcalves@gmail.com 
sanitária brasileira, mas também relatos incomuns aos leitores habituais desse tema, como a referência as duas comissões instaladas respectivamente em 1983 (Comissão Parlamentar de Inquérito da Câmara dos Deputados) e 1987 (Comissão Especial do Senado Federal), com o objetivo de apurar a dívida externa brasileira; a crítica a teoria das gerações/dimensões dos direitos fundamentais e a proposição de interpretá-los de modo amplo, respeitando as peculiaridades inerentes a cada um desses direitos, sem que haja uma restrição a sua análise às características de cada uma das gerações apresentadas.

Ainda no Capítulo 1, apresenta a influência do neoliberalismo para as políticas públicas de saúde no Brasil. Destaca a instalação tardia dessas medidas no Brasil face a resistência do empresariado industrial em se submeter ao capital financeiro comandado por grandes empresas transnacionais; a forte oposição formada por parlamentares progressistas e grupos da esquerda que propugnavam por mudanças estruturantes como reforma agrária, urbana e universitária, e que portanto, eram diametralmente opostas àquelas defendidas pelo neoliberalismo; e a própria Constituição Cidadã, que estabeleceu um novo paradigma de proteção social, especialmente com a inclusão de um capítulo dedicado à Ordem Social.

O autor aborda ainda a eleição do Presidente Lula, almejada por muitos como a via possível para uma inflexão mais progressista do Estado; e a frustação de muitos dos seus apoiadores com as sucessivas medidas implementadas que constituíram retrocessos nos planos sociais, políticos e econômicos. Destaca ainda as consequências dessas medidas para o próprio Partido dos Trabalhadores (PT), como a ruptura interna, saída de vários parlamentares, e fundação de um novo partido de esquerda, o Partido Socialismo e Liberdade (PSOL), apoiado nos ideais originários do PT.

Destaca a divergência doutrinária acerca do tipo de governo empreendido pelo presidente Lula, se fundamentado em um receituário pós-neoliberal e neodesenvolvimentista (Pochmann, 2010; Sader et al, 2013; Mercadante, 2010; Dulci, 2013, etc.) ou se efetivamente neoliberal, inclusive quando analisado as políticas de transferência de renda, visto que seguiam a lógica imposta por organismos internacionais como o Banco Mundial e Fundo Monetário Internacional (Gonçalves, 2013; Arruda Jr, 2012; Arcary, 2012).

Sobre o governo Dilma, que foi herdeiro do projeto político de seu antecessor, o autor destaca especificamente as manifestações populares ocorridas em junho de 2013, em que 
se reivindicava melhorias nas políticas públicas de saúde, educação, transporte, etc. em detrimento aos investimentos vultosos realizados pelo Estado brasileiro para a realização de megaeventos (copa do mundo de futebol e olimpíadas). Como a obra foi editada antes do impeachment, apresenta apenas a exigência dessa punição frente ao descontentamento geral com as inúmeras ações alinhadas a retrocessos trabalhistas, previdenciários, a alta inflação, e aos escândalos de corrupção envolvendo políticos do alto escalão ligados ao governo, e importantes empresas públicas, especialmente a Petrobrás.

Especificamente sobre as políticas de saúde empreendidas ao longo dos governos de Lula e Dilma, o autor apresenta, de forma inicial, a expectativa existente sobre a retomada do projeto de Reforma Sanitária, concebido em sua forma original, vez que os quadros do setor saúde ligados ao PT era composto de históricos sanitaristas. Entre as divergências doutrinárias sobre a caracterização das políticas de saúde, se avançadas ou retrógradas, o autor elenca os seguintes fatos ocorridos durante o primeiro governo Lula: política de saúde Bucal com o Programa Brasil Sorridente (ampliação das equipes de saúde bucal), aliado a aumento significativa de centros de especialidades e laboratórios regionais de próteses dentárias; o Serviço de Atendimento Móvel de Urgência (SAMU), ligado à Política de Atenção às Urgências e Emergências; e o Programa Farmácia Popular, que subsidia a compra de medicamentos.

Outros avanços relatados nesse período dizem respeito a valorização da atenção básica como política orientadora do Sistema Único de Saúde, e o olhar sobre a tema dos medicamentos, com a regulação de preços pela Câmera de Regulação de Mercado de Medicamentos (CAMED), a política de medicamentos genéricos e a realização da primeira Conferência Nacional de Medicamentos e Assistência Farmacêutica.

No segundo mandato, observa-se outra linha de ação, fundamentado no neodesenvolvimentismo sanitário, com incentivos ao complexo médico-hospitalar. Apresenta então os programas oficiais como o Programa de Aceleração do Crescimento da Saúde (Programa Mais Saúde), com o objetivo de desenvolver o complexo médicoindustrial da saúde, gerando emprego e renda, e a tentativa de realização da associação virtuosa entre saúde, desenvolvimento e inovação; e, a criação de empresas públicas na área de pesquisa e desenvolvimento em saúde, como a Empresa Brasileira de Hemoderivados e Biotecnologia (Hemobrás). 
Aponta ainda para a expansão da estratégia de saúde da família e a criação dos Núcleos de Apoio à Saúde da Família (NASF) como apoio às equipes multiprofissionais, guardando assim coerência com o incentivo prestado à atenção básica durante o primeiro mandato. Como principais avanços elencam as melhorias dos determinantes e condicionantes sociais da saúde.

O autor também colaciona as críticas ao desempenho das políticas de saúde implementadas no governo Lula externadas por Bravo (2009), Batista Jr. (2010) e Bahia e Scheffer (2013), definindo-as como "deforma sanitária" (p. 93), vez que fortaleceu a política neoliberal e o incentivo aos planos e seguros privados de saúde, em detrimento a baixa valorização das deliberações tomadas nas conferências e conselhos de saúde. Nesse sentido, o autor faz coro as críticas e reconhece os impactos negativos que levam a desmobilização dos diversos setores em defesa do SUS.

Na sequência, destaca que o Brasil é o único país com sistema universal em que o gasto privado é maior que o gasto público, o que reforça o histórico subfinanciamento do SUS. Afinal, apesar da magnitude do texto constitucional que reconheceu a saúde como um direito social de cidadania, com forte influência welferiana, a Carta Magna não garantiu uma base material de financiamento compatível com o novo sistema de saúde.

No tocante ao governo Dilma, o principal destaque é o Programa Mais Médicos, especificamente na dimensão do provimento emergencial, para suprir os vazios assistenciais em áreas vulneráveis. O ponto de retrocesso é a aprovação da Lei no 13.097/2015, que, segundo autor, favoreceu o complexo médico-industrial-financeiro, pois passou a permitir a entrada de capital financeiro internacional na assistência à saúde.

O Capítulo 2 se propõe a exemplificar e discutir alguns retrocessos no âmbito sanitário, sendo dois no campo doutrinário (mínimo existencial e reserva do possível), e dois no plano institucional (criação da Empresa Brasileira de Serviços Hospitalares EBSERH, e a não aprovação do Projeto Saúde + 10).

Inicialmente, a obra apresenta uma descrição da construção dos conceitos do mínimo existencial e da reserva do possível e sua "tradução deslocada" para o contexto brasileiro, para então afirma-los como retrocessos no campo sanitário. No caso do mínimo existencial, a teoria vem sendo utilizada para restringir o direito à saúde ao âmbito da atenção primária, e restringir o alcance dos princípios da universalidade e integralidade. Em um passado recente foi bastante utilizada nos tribunais como argumento de defesa da 
Fazenda Pública para enfrentamento do fenômeno da judicialização da saúde, porém, atualmente, a tese não tem sido recepcionada nos tribunais nacionais.

Ponto de destaque é a construção argumentativa do autor para defender a sua tese de retrocesso sanitário ao comparar o conceito de mínimo existencial com o de básico social, utilizando as contribuições de Pereira (2011), que por sua vez se apoia em Hayek, Rawls, e Gough \& Doyal. Afirma o autor que "o básico social se diferencia do mínimo existencial no sentido de que é uma política estrutural, exigindo reformas de base, como a efetivação de uma reforma sanitária com base em nossa Constituição [...]” (p. 113).

Já a avaliação do conceito da reserva do possível como retrocesso sanitário, o autor parte do pressuposto que inexiste critérios objetivos que possam avalizar a existência de recursos públicos insuficientes para a efetivação dos direitos sociais de natureza prestacional, como a saúde. Assim, o uso desse argumento sem comprovação empírica é característica de setores que não se comprometem com a saúde enquanto um direito de cidadania.

Sobre os retrocessos de natureza institucional, o autor destaca a criação da Empresa Brasileira de Serviços Hospitalares por um governo de esquerda, apesar das manifestações contrária advindas dos movimentos em defesa da saúde, cristalizado nas recomendações advinda da XIV Conferência Nacional de Saúde, em que a plenária reprovou toda e qualquer forma de terceirização da gestão de serviços públicos de saúde para empresas, fundações privadas e organizações sociais.

Esse fato, por si só, representa a dissociação existente entre o Poder Executivo, o Poder Legislativo, e a vontade popular, vez que a Conferência de Saúde é a arena por excelência da participação da comunidade, contando com a representação de vários segmentos sociais, e que detém a responsabilidade de avaliar a situação de saúde e propor diretrizes para formulação de política públicas.

Outro episódio em que o governo "deu às costas" a manifestação popular foi no campo do financiamento da saúde, quando houve uma ampla movimentação para garantir um percentual mínimo de investimento federal para a saúde, denominado "Saúde + 10", que consistia na aplicação mínima de $10 \%$ (dez por cento) da receita corrente bruta da União, para a área da saúde. Apesar da coleta de 2,2 milhões de assinaturas em torno desse propósito, gerando um projeto de lei de iniciativa popular (PLP nำ31/2013), a aprovação da Emenda Constitucional no 86/2015 enfraqueceu o pleito vez que promoveu a 
alteração do financiamento para estabelecer percentuais mínimos e de caráter progressivo (iniciou com 13,2\% e até 2020 deve atingir 15\%), mas com base na receita corrente líquida.

Esse tema está diretamente relacionado com um assunto recente e bastante polêmico que é a discussão da PEC 55 (PEC 241), que prevê o congelamento das despesas primárias da União, pelos próximos 20 anos, garantindo o reajuste dos orçamentos das áreas sociais com base no cálculo da inflação do período.

Conclui-se que o que era uma reivindicação em torno da ampliação do financiamento da saúde se tornou uma sucessão de constrangimentos para o direito à saúde, provocado por fatores extras setoriais, especialmente a busca pelo equilíbrio macroeconômico.

O Capítulo 3 contém a grande inovação da obra, que é a apresentação do princípio da proibição do retrocesso social e a auditoria constitucional da dívida pública como alternativas de enfrentamento aos retrocessos sanitários.

De modo bastante didático, o autor explica a importância de se abordar os princípios jurídicos na interpretação de textos normativos - como no caso do arco normativo do direito à saúde - e as consequências para o contexto social, trazendo argumentos de Esser (1961), Larenz (2001), Dworkin (2010) e Alexy (2011).

Passa então a apresentação do princípio da proibição do retrocesso social, e todo o seu processo de desenvolvimento na Europa - Alemanha, Itália e Portugal - e retoma a interpretação desse mesmo princípio na Europa atual, em um contexto de pós-crise imobiliária de 2007/2008, e que resultou em graves consequências para os direitos sociais.

Aborda os problemas intrínsecos ao capitalismo e os principais retrocessos advindos com a crise econômica, a saber: radicalização do capital financeiro; enfraquecimento do capital produtivo e industrial; esforço para gerar superávit primário; deslocamento de recursos do orçamento social para o pagamento de dívidas e juros; superexploração dos trabalhadores para geração de mais valia e restrições de direitos sociais.

Ponto curioso é a visão dialética apresentada pelo autor sobre as consequências dos retrocessos sociais na seara política. De um lado o atentado ao Estado Democrático de Direito, e como anverso dessa moeda, o ressurgimento das lutas sociais, especialmente nos países com crise mais intensa.

Nesse contexto, a saúde é diretamente atingida, especialmente com a redução do seu financiamento público, ao mesmo tempo em que os serviços públicos de saúde 
passam a receber um fluxo maior de pessoas, especialmente em virtude da redução dos gastos das famílias, empresas e indivíduos com planos e seguros privados de saúde.

No contexto brasileiro, especificamente, a discussão acerca do princípio da proibição do retrocesso social ainda é incipiente, e o autor recomenda cautela de modo a não haver uma transposição mecanicista de um conceito elaborado em uma sociedade determinada, para o Brasil, com suas realidades sócio-político-econômica específicas. "Deve-se lembrar que uma coisa é a aplicação de uma teoria em um modelo de país 'central', outra coisa é a aplicação desta mesma teoria em um país 'periférico'” (p. 162).

Todavia, recomenda o seu emprego no combate às medidas de retrocesso perpetradas contra o SUS, vez que o princípio tem a função de "garantir o grau de concretização dos direitos fundamentais sociais [...], não permitindo, de forma alguma, que se retroceda a um quadro sócio-jurídico já esgotado, distante do ideal proposto pela Carta Magna" (p. 169).

A atuação na defesa do direito sanitário deve se dar em duas frentes. A primeira na defesa da própria Constituição, que de modo ímpar albergou os princípios do direito à saúde e delineou a forma de organização das ações e serviços públicos de saúde; e a segunda é acompanhar pari passu os Poderes da República, para que não promovam atos que levem a retrocessos sociais, enfatizando então a força e a importância da mobilização e participação popular em defesa da saúde, da mesma forma que ocorreu quando da reivindicação por um novo sistema de saúde.

Outra alternativa proposta é a auditoria constitucional da dívida, vez que o governo vem utilizando, nos últimos tempos, grande parte de seu orçamento para o pagamento de juros e amortizações da dívida externa. Desse modo, uma vez que há previsão constitucional de tal instrumento (art. 26, ADCT), necessário colocá-lo em prática, especialmente agora em virtude da crise econômico e do forte ajuste fiscal que avizinha

Ademais, argumenta o autor, a auditoria da dívida - constatando irregularidades e abusos - seria capaz de redirecionar os recursos públicos para setores sociais, especialmente a saúde, solucionando o problema histórico do subfinanciamento do SUS. Em um contexto de forte crise econômica, importante trazer à colação a afirmação de 
Carlos Ocké-Reis ${ }^{3}$ sobre a natureza anticíclica e anti-inflacionária do financiamento da saúde, contribuindo para a mitigação das desigualdades sociais e restabelecimento da coesão social.

Ainda sobre o ponto da auditoria constitucional da dívida, o autor apresenta então alguns países que a realizaram - Equador, Argentina e Grécia - sendo que apenas o primeiro fez uma auditoria oficial, e que foi submetida a Cortes Internacionais. O resultado para o país foi positivo, com o aumento do investimento público em saúde, o que nos deixa um alento sobre alguns possíveis caminhos existentes ao longo dessa árdua disputa entre capital e direitos sociais.

No capítulo destinado às considerações finais, fica claro para o autor que os avanços foram tímidos, mas que os retrocessos políticos, sociais e institucionais foram desinibidos, motivo pelo qual demonstra a necessidade de transformações estruturais para que os avanços e conquistas insertos no texto constitucional sejam cumpridos e respeitados. Cobra, do movimento sanitário, a adesão às alternativas radicais propugnadas na obra, vez que estão devidamente fundamentadas na própria Constituição Cidadã.

Ademais, deixa claro que no momento atual de crise econômica, política e de descenso de participação, é necessário ao movimento sanitário, sair da zona de conforto e retomar o caráter protagonista, transformador e reivindicatório que já foi a sua característica indelével.

A obra possui um conteúdo político e econômico forte, como não poderia deixar de ser ao se analisar um tema que tem forte imbricamento social e econômico. A proposição de alternativas até então pouco debatidas no plano doutrinário entre os autores festejados, demonstra que existem searas pouco exploradas e que podem significar alternativas possíveis (?) para o resgate do direito à saúde como originariamente concebido. Necessário investigá-las com mais propriedade para compreender o real alcance desses instrumentos e os impactos que podem gerar na garantia do direito à saúde.

\footnotetext{
3 Ocké-Reis, C. Qual a magnitude do gasto tributário em saúde? (Acesso 15 nov 2016). Disponível em:
} http://cebes.org.br/2014/12/carlosocke-escreve-sobre-gasto-tributario-em-saude/ 
Como ponto marcante, a necessidade do movimento sanitarista se reinventar, não só no aspecto de mobilização social, mas, sobretudo com novas proposições e alternativas que levem a construção de uma consciência social sanitária.

Recebido em: 5/12/2016 Aprovado em: 12/12/2016

\section{Como citar este artigo:}

Alves SMC. Avanços e retrocessos do direito à saúde no Brasil. Revista Cadernos Ibero-Americanos de Direito Sanitário. 2016 jul./set, 5(3):186-194. 